University of Montana

ScholarWorks at University of Montana

$9-1-1976$

\title{
A Comparison of the Rough Sphere Rotational Diffusion Model with Experimental Results for Liquid Methyl lodide
}

Dane R. Jones

University of Utah

Scott L. Whittenburg

University of Montana - Missoula, scott.whittenburg@umontana.edu

C. H. Wang

University of Utah

Follow this and additional works at: https://scholarworks.umt.edu/chem_pubs

Part of the Biochemistry Commons, Chemistry Commons, and the Physics Commons Let us know how access to this document benefits you.

\section{Recommended Citation}

Jones, Dane R.; Whittenburg, Scott L.; and Wang, C. H., "A Comparison of the Rough Sphere Rotational Diffusion Model with Experimental Results for Liquid Methyl Iodide" (1976). Chemistry and Biochemistry Faculty Publications. 69.

https://scholarworks.umt.edu/chem_pubs/69

This Article is brought to you for free and open access by the Chemistry and Biochemistry at ScholarWorks at University of Montana. It has been accepted for inclusion in Chemistry and Biochemistry Faculty Publications by an authorized administrator of ScholarWorks at University of Montana. For more information, please contact scholarworks@mso.umt.edu. 


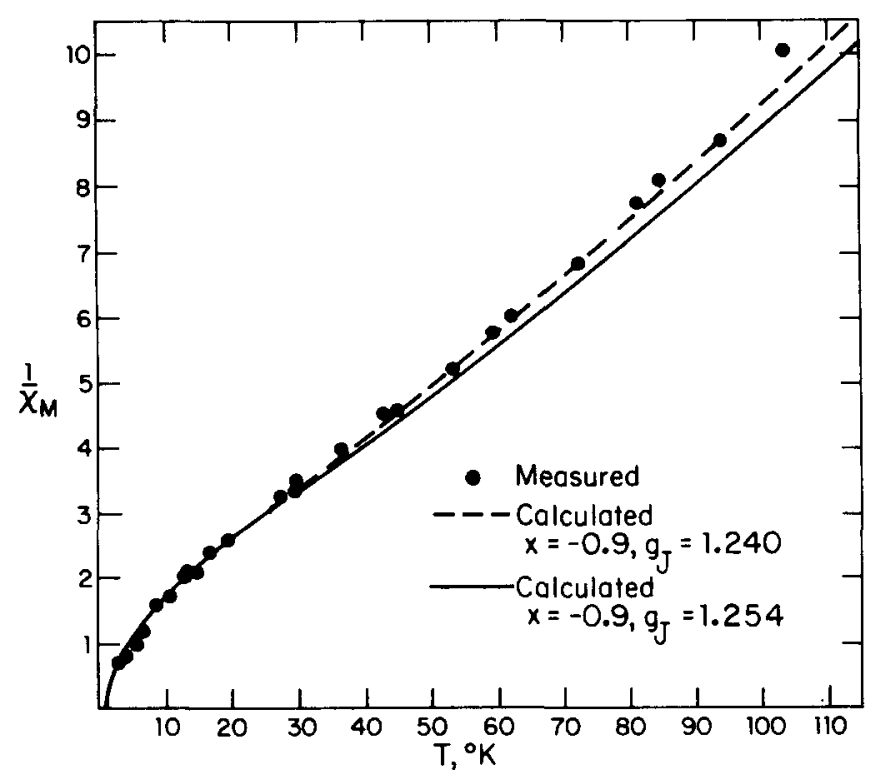

FIG. 1. Data fitted by calculated reciprocal magnetic susceptibilities for $\mathrm{Cs}_{2} \mathrm{NaY}(\mathbf{C f}) \mathrm{Cl}_{6}$.

Fock) calculation given by Lewis et al. ${ }^{12}\left\langle r^{4}\right\rangle \approx 5$ a. u. and $\left\langle r^{6}\right\rangle \approx 35$ a. u. for $\mathrm{Cf}^{3+}$, so $A_{4}=(90 \pm 30) \mathrm{cm}^{-1} / \mathrm{a}$. u. and $A_{6}=(1.7 \pm 0.7) \mathrm{cm}^{-1} / \mathrm{a} . \mathrm{u}$. The corresponding values for $\mathrm{Dy}^{3+}$ are $A_{4}=(120 \pm 20) \mathrm{cm}^{-1} / \mathrm{a}$. u. and $A_{6}=(4.6 \pm 2)$ $\mathrm{cm}^{-1} / \mathrm{a}$. u. ${ }^{9}$ Given the relatively large uncertainties in both these cases, the values of $A_{4}$ and $A_{6}$ for $\mathrm{Cf}^{3+}$ and. for $\mathrm{Dy}^{3+}$ are approximately equal. Thus, the increased crystal field effects in the actinide compounds are primarily due to the larger values for the radial parameters $\left\langle r^{n}\right\rangle$.

A simple comparison of the radial parameters $\mathrm{Cf}^{3+}$ and $\mathrm{Dy}^{3+}$ would have suggested a much larger sixthorder contribution in the actinides than in the lanthanides due to the increased $\left\langle r^{6}\right\rangle$ from the more extended $5 f$ electrons. The effect of the larger $5 f\left\langle r^{B}\right\rangle$ is largely counteracted by the strong reduction in $\gamma$ when that parameter is obtained from intermediate coupling wavefunctions. A previous magnetic susceptibility study ${ }^{2}$ of the trivalent actinide compounds $\mathrm{Cs}_{2} \mathrm{NaMCl}_{6}\left(\mathrm{M}=\mathrm{U}^{3+}\right.$, $\mathrm{Pu}^{3+}$, etc.) was interpreted as consistent with a range in the ratio $A_{B}^{0}\left\langle r^{6}\right\rangle / A_{6}^{0}\left\langle r^{4}\right\rangle$ between 0.31 and 0.034 . The present value for $\mathrm{Cf}^{3+}, 0.18$, falls within this range.

The above calculation of $\chi$ assumes first-order theory and does not include configuration interaction or $J$-mixing contributions. Substantial contributions from configuration interactions were found in a spectral study ${ }^{13}$ of $\mathrm{CfCl}_{3}$, and configuration interaction could alter the relative spacing of the crystal field levels from the LLW first-order model or even the ordering of the levels, as found in EPR studies ${ }^{14}$ on $\mathrm{Pu}^{3+}$. Configuration interactions might be the cause of the divergence between the data and theory above $50^{\circ} \mathrm{K}$. Because the next higher state in $\mathrm{CfCl}_{3}$ was found ${ }^{12}$ at $6500 \mathrm{~cm}^{-1}, J \mathrm{mix}-$ ing is presumed to be unimportant.

Finally, the present analysis gives a $\Gamma_{6}$ crystal field ground state for $\mathrm{Cf}^{3+}$, with a $\Gamma_{8}^{(1)}$ level as the first excited state at $\sim 50 \mathrm{~cm}^{-1}$. The total crystal field splitting is calculated to be approximately $860 \mathrm{~cm}^{-1}$.

* The information contained in this article was developed during the course of work under Contract No. AT (07-2)-1 with the U. S. Energy Research and Development Administration.

${ }^{1}$ L. R. Morss, M. Siegel, L. Stenger, and N. Edelstein, Inorg. Chem. 8, 1771 (1970).

${ }^{2}$ M. E. Hendricks, E. R. Jones, Jr., J. A. Stone, and D. G. Karraker, J. Chem. Phys. 60, 2095 (1974).

${ }^{3}$ M. V. Hoehn and D. G, Karraker, J. Chem. Phys. 60, 393 (1974).

${ }^{4}$ N. Edelstein and D. G. Karraker, J. Chem. Phys. 62, 939 (1975).

${ }^{5}$ R. W. Schwartz and N. J. Hill, J. Chem. Soc. Faraday 2, 114 (1974).

${ }^{6}$ R. W. Schwartz and P. N. Schatz, Phys. Rev. B 8, 3229 (1973).

${ }^{7}$ B. D. Tofield and H. P. Weber, Phys. Rev. B 10, 4560 (1974).

${ }^{8}$ K. R. Lea, M. J. M. Leask, and W. P. Wolf, J. Phys. Chem. Solids 23, 1381 (1962).

${ }^{9}$ B. D. Dunlap and G. K. Shenoy, Phys. Rev. B 12, 2716 (1975).

${ }^{10}$ D. O. Campbell, J. Inorg. Chem. 35, 3911 (1973).

${ }^{11}$ G. R. Choppin, B. G. Harvey, and S. G. Thompson, J. Inorg Nucl. Chem. 2, 66 (1956).

${ }^{12}$ W. B. Lewis, J. B. Mann, D, A. Liberman, and D. T. Cromer, J. Chem. Phys. 53, 809 (1970).

${ }^{13}$ W. T. Carnall, S. Fried, and F. Wagner, Jr., J. Chem. Phys. 58, 1938 (1973).

${ }^{14}$ N. Edelstein, H. F. Mollet, W. C. Easley, and R. J. Mehlhorn, J. Chem. Phys. 51, 3281 (1969).

\title{
A comparison of the rough sphere rotational diffusion model with experimental results for liquid methyl iodide
}

\author{
Dane R. Jones, ' S. L. Whittenburg, and C. H. Wang ${ }^{\dagger}$ \\ Department of Chemistry, University of Utah, Salt Lake City, Utah 84112
}

(Received 2 April 1976)

The rotational motion of molecules in the liquid state has been described using several models. Chandler has recently developed a theory which describes rotational motion in terms of a system of rough hard spheres interacting through binary collisions. ${ }^{1}$ This model, which provides a microscopic derivation of Gordon's $J$-diffusion model, ${ }^{2}$ has been tested against molecular dynamics results ${ }^{1,3}$ and spin-spin and spin-lattice NMR relaxation time results. 1 To our knowledge, no detailed comparisons have been made between Chandler's 
theory and Raman and infrared experimental results. It is the purpose of this note to present such a comparison. We use methyl iodide for testing the theory, as both infrared and Raman data for this molecular liquid are accurately known.

Chandler's rough hard sphere model pertains strictly to a system of spherical particles undergoing instantaneous collisions. As a result of a collision, one particle transfers angular momentum to the particle with which it collides. For smooth spheres, the collisions are still instantaneous but no transfer of angular momentum takes place. A realistic model for nonspherical molecules, such as $\mathrm{CH}_{3} \mathrm{I}$, would probably lie between these extremes of "smooth" and "rough", as was pointed out by Chandler. In his paper, Chandler gives theoretical expressions for the rotational correlational functions $C_{1}(t)$ and $C_{2}(t)$ and the zero-frequency relaxation times $\tau_{1}$ and $\tau_{2}$ which correspond to the experimental infrared and Raman zero-frequency rotational relaxation times, respectively. The final forms of the equations are

$$
\tau_{1}=\int_{0}^{\infty} C_{1}(t) d t=\tau_{\omega} x e^{x} E_{1}(x) /\left[1-x e^{x} E_{1}(x)\right]
$$

and

$\tau_{2}=\int_{0}^{\infty} C_{2}(t) d t=\tau_{\omega}\left[1+3 y e^{y} E_{1}(y)\right] / 4\left\{1-\frac{1}{4}\left[1+3 y e^{y} E_{1}(y)\right]\right\}$

where $x=I / 2 \tau_{\omega}^{2} k T, y=I / 8 \tau_{\omega}^{2} k T, I$ is the moment of inertia, $T$ is the absolute temperature, and $k$ is Boltzmann's constant. $\tau_{\omega}$ is essentially the angular momentum correlation time and is related to the Enskog relaxation time $\tau_{E}$ through the relation $\tau_{\omega}^{-1}=a \tau_{E}^{-1}$, where $a$ is the roughness of the hard sphere. For perfectly smooth hard spheres $a=0$, and for perfectly rough hard spheres $a=\left[\left(4 I / m d^{2}\right)+1\right]^{-1}$, where $m$ is the molecular mass and $d$ is the molecular diameter. $\tau_{E}$ is given by

$$
\tau_{E}^{-1}=\frac{8}{3}(\pi k T / m)^{1 / 2} \rho d^{2} g,
$$

where $\rho$ is the particle density. $g$, the contact value of the hard sphere radial distribution function, equals $(2-\eta) / 2(1-\eta)^{3}$ with $\eta$, the packing fraction, equal to $(\pi / 6) \rho d^{3}$. The function $E_{1}(z)$ is given by

$$
E_{1}(z)=\int_{z}^{\infty} \frac{e^{-u}}{u} d u
$$

Chandler compared the predictions of his theory to molecular dynamics results for liquid nitrogen. Nitrogen is a linear molecule with a length-to-width ratio of $\sim 1.3$. The theoretical values of $\tau_{2}$ agreed with the molecular dynamics results for a roughness of 0.43 (the perfectly rough sphere roughness for $\mathrm{N}_{2}$ is $\sim 0.83$ ). The theoretical $\tau_{1}$ values were generally lower than the molecular dynamics results. O'Dell and Berne have performed molecular dynamics experiments for a rough sphere fluid and compared the results to the predictions of Chandler's theory. ${ }^{3}$ The theoretical relaxation times were consistently larger than the molecular dynamics times. DeZwann and Jonas have studied $\mathrm{CCl}_{3} \mathrm{~F}$ and $\mathrm{SF}_{6}$ using spin-echo and spin-lattice NMR techniques." From the spin-lattice relaxation time measurements,

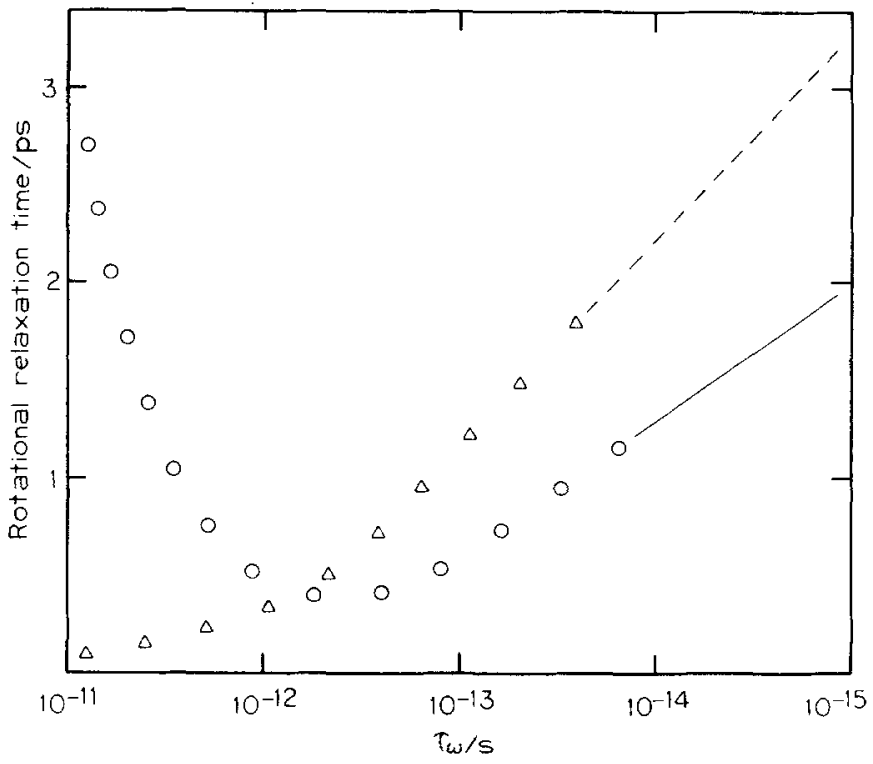

FIG. 1. Rotational relaxation times versus angular momentum relaxation time for methyl iodide at $283.7 \mathrm{~K}: \Delta \Delta \Delta, \tau_{1}$ (infrared); --., $\tau_{1}$ (extrapolated); $\infty \circ, \tau_{2}$ (Raman); - - $\tau_{2}$ (extrapolated).

experimental angular momentum cor relation times were obtained. Hard sphere diameters were calculated from the density dependent $\tau$ values and these diameters were used in a calculation, using Chandler's model, of the self-diffusion constants. The theoretical self-diffusion constants were in agreement with experimental values obtained from spin-echo measurements, when the hard sphere diameters were allowed to vary with temperature.

We have calculated theoretical rotational relaxation times for liquid $\mathrm{CH}_{3} \mathrm{I}$ at $283.7 \mathrm{~K}$ for a wide range of $\tau_{\omega}$ values using Eqs. (1) and (2). The results are given in Fig. 1. Experimental $\tau_{1}$ (infrared) and $\tau_{2}$ (Raman) single particle rotational relaxation times for methyl iodide have been reported by several authors. ${ }^{5}$ Jones, Andersen, and Pecora reported $\tau_{1}$ and $\tau_{2}$ values of 3.1 \pm 0.4 and $1.5 \pm 0.4 \mathrm{ps}$, respectively, at $283.7 \mathrm{~K}$. These values were obtained from the exponential part of the corresponding correlation functions. Zero-frequency relaxation times obtained from the experimental correlation functions of Jones et al. were the same as those obtained from the exponential part of the correlation functions within experimental uncertainty. ${ }^{5,6}$ Theoretical $\tau_{1}$ and $\tau_{2}$ relaxation times in agreement with the experimental values can be obtained only for a very small value of $\tau_{\omega}$. For $\tau_{\omega} \simeq 2.5 \times 10^{-15} \mathrm{~s}$, the plots in Fig. 1 yield $\tau_{1}$ and $\tau_{2}$ values of 2.9 and $1.6 \mathrm{ps}$, respectively. These theoretical rotational relaxation times seem to agree fairly well with the experimental values given above. However, such a small $\tau_{\omega}$ value does not appear to be physically reasonable. Lyerla, Grant, and Wang reported an experimental angular momentum relaxation time for $\mathrm{CH}_{3} \mathrm{I}$ of $0.12 \mathrm{ps},{ }^{7}$ which is a factor of 50 greater than the $\tau_{\omega}$ obtained from Fig. 1. To investigate further, we used the $\tau_{\omega}=2.5 \times 10^{-15} \mathrm{~S}$ value and various values of the molecular diameter $d$ to calculate values for the packing fraction $\eta$, Enskog 
TABLE I. Parameters for $\mathrm{CH}_{3} \mathrm{I}$ at $283.7 \mathrm{~K}$ using $\tau_{\omega}=2.5$ $\times 10^{-15} \mathrm{~s}$.

\begin{tabular}{|c|c|c|c|c|}
\hline $\begin{array}{l}\text { Molecular } \\
\text { diameter } \\
d(\AA) \\
\end{array}$ & $\begin{array}{l}\text { Packing } \\
\text { fraction } \\
\eta\end{array}$ & $\begin{array}{l}\text { Enskog } \\
\text { relaxation time } \\
\tau_{E}(\mathrm{~s})\end{array}$ & $\begin{array}{l}\text { Roughness } \\
a^{\mathbf{a}}\end{array}$ & $\begin{array}{l}\text { Roughness } \\
\text { for perfectly } \\
\text { rough hard } \\
\text { sphere }^{\mathrm{b}} \\
\end{array}$ \\
\hline 3.5 & 0.22 & $6.3 \times 10^{-13}$ & 253 & 0.87 \\
\hline 4.2 & 0.38 & $2.9 \times 10^{-13}$ & 116 & 0.90 \\
\hline 4.8 & 0.56 & $8.7 \times 10^{-14}$ & 35 & 0.92 \\
\hline 5.2 & 0.71 & $2.3 \times 10^{-14}$ & 9.3 & 0.93 \\
\hline 5.55 & 0.87 & $2.4 \times 10^{-15}$ & 0.95 & 0.94 \\
\hline 5.75 & 0.96 & $5.2 \times 10^{-17}$ & 0.021 & 0.95 \\
\hline
\end{tabular}

${ }^{\mathrm{a}} a=\tau_{E} / \tau_{\omega} . \quad{ }^{\mathrm{b}} a=\left[\left(4 I / m d^{2}\right)+1\right]^{-1}$.

relaxation time $\tau_{E}$, and roughness $a$. We also calculated the roughness of a perfectly rough hard sphere for the different diameters. The results are given in Table I. For diameters less than $5.5 \AA$, the $a$ values calculated from $\tau_{E}$ and $\tau_{\omega}$ are much larger than the roughness for the corresponding perfectly rough hard sphere. For physically reasonable roughness and diameter values, the packing fraction is much too great; e.g., for the most compact packing, face-centered cubic, $\eta=0.74 .^{8}$

Thus, this small value of $\tau_{\omega}$, while giving $\tau_{1}$ and $\tau_{2}$ values in agreement with experimental results, is physically unreasonable. The theoretical $\tau_{2}$ value for $\tau_{\omega}=4 \times 10^{-12} \mathrm{~s}$ agrees with the experimental value, but the corresponding theoretical $\tau_{1}$ value is a factor of 20 too small. We conclude that there is no physically acceptable value of $\tau_{\omega}$ which can explain the experimental $\tau_{1}$ and $\tau_{2}$ data of methyl iodide. It would be interesting to use high pressure to investigate the density dependence of $\tau_{1}$ and $\tau_{2}$ in an attempt to learn more about the nature of molecular motion in liquids composed of nonspherical molecules.

We are grateful to Professor D. Chandler for a critical review of the manuscript and for very valuable discussions. We also acknowledge the Donors of The Petroleum Research Fund, administered by the American Chemical Society, for the support of this research.

*Present address: Department of Chemistry, California Polytechnic State University, San Luis Obispo, CA. 93407.

${ }^{\dagger}$ Alfred P. Sloan Foundation Fellow (1973-1977).

${ }^{1}$ D. Chandler, J. Chem. Phys. 60, 3508 (1974).

${ }^{2}$ R. G. Gordon, J. Chem. Phys. 44, 1830 (1966).

${ }^{3}$ J. O'Dell and B. J. Berne, J. Chem. Phys. 63, 2376 (1975).

${ }^{4} \mathrm{~J}$. DeZwann and J. Jonas, J. Chem. Phys. 62, 4036 (1975); 63, 4606 (1975).

${ }^{5}$ See, for example, D. R. Jones, H. C. Andersen, and R. Pecora, Chem. Phys. 9, 339 (1975); R. B. Wright, M. Schwartz, and C. H. Wang, J. Chem. Phys. 58, 5125 (1973); F. J. Bartoli and T. A. Litovitz, J. Chem. Phys. 56, 413 (1972).

${ }^{6} \mathrm{D}$. R. Jones (unpublished work).

${ }^{7}$ J. R. Lyerla, D. M. Grant, and C. H. Wang, J. Chem. Phys. 65, 4676 (1971).

${ }^{8} \mathrm{C}$. Kittel, Introduction to Solid State Physics (Wiley, New York, 1971), 4th ed., p. 41.

\title{
Barriers to internal rotation obtained by pseudopotential calculations
}

\author{
Carl S. Ewig and John R. Van Wazer \\ Department of Chemistry, Vanderbilt University, Nashville, Tennessee 37235 \\ (Received 1 March 1976)
}

In recent studies, ${ }^{1-5}$ we have shown that the use of our molecular pseudopotential theory gives results that are comparable to those obtained with the same basis set in a full SCF calculation for all the molecular properties we have investigated. Here we describe the application of this method (the NOCOR procedure) to the calculation of barriers to molecular internal rotation.

The rotational barriers for a valence isoelectronic series-ethane, methylsilane, methylgermane, and methylstannane-are presented in Table I, in which the results of the NOCOR method are seen to compare well with those obtained by an equivalent full SCF calculation and with the best experimental values. Both the pseudopotential and the full SCF calculations were carried out in a minimum-Slater basis set, with each Slater orbital being expanded into a set of four Gaussian functions. The Slater exponents used in these calculations were molecularly optimized for ethane ${ }^{7}$ and methylsilane. ${ }^{8}$ For the two remaining molecules, the Slater exponents for the methyl hydrogens and the carbon atoms were chosen to be equal to those obtained for the methyl group in methylsilane. Atom-optimized Slater exponents were employed for the germanium and tin atoms, and their attached hydrogens were assumed to have an exponent of 1.0. On going from the staggered to the eclipsed

TABLE I. Comparison of total barriers to internal rotation computed by pseudopotential theory (NOCOR method), conventional self-consistent-field results, and experiment. All values in calories.

\begin{tabular}{lccc}
\hline Molecule & NOCOR & SCF $^{\mathrm{a}}$ & Experiment \\
\hline $\mathrm{C}_{2} \mathrm{H}_{6}$ & 3010 & 3140 & $2928 \pm 25^{\mathrm{b}}$ \\
$\mathrm{CH}_{3} \mathrm{SiH}_{3}$ & 1220 & 1520 & $1665 \pm 50^{\mathrm{C}}$ \\
$\mathrm{CH}_{3} \mathrm{GeH}_{3}$ & 1330 & 1280 & $1239 \pm 25^{\mathrm{d}}$ \\
$\mathrm{CH}_{3} \mathrm{SnH}_{3}$ & 690 & $\cdots$ & $650 \pm 30^{\mathrm{e}}$ \\
\hline \hline
\end{tabular}

${ }^{2} \mathrm{SCF}$ values for the $\mathrm{C}_{2} \mathrm{H}_{6}$ and $\mathrm{CH}_{3} \mathrm{SiH}_{3}$ barriers

have also been presented in Refs. 6-8.

${ }^{b} \mathrm{~S}$. Weiss and G. E. Leroi, J. Chem. Phys. 48, 962 (1968).

${ }^{c}$ D. R. Herschbach, J. Chem. Phys. 31, 91 (1959).

Reference 11.

${ }^{\mathrm{E}}$ Reference 12 . 